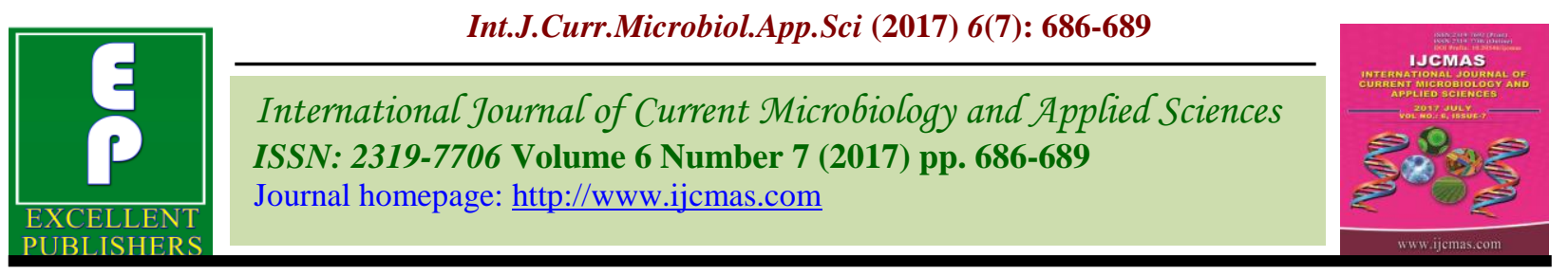

Original Research Article

https://doi.org/10.20546/ijcmas.2017.607.084

\title{
Study of Opportunistic Infections in HIV Seropositive Patients in Tertiary Care Hospital, Maharashtra, India
}

\author{
Virendra S. Kolhe ${ }^{1 *}$ and Sanjay R. More ${ }^{2}$ \\ ${ }^{1}$ Department of Microbiology, GMC, Chandrapur, India \\ ${ }^{2}$ Department of Microbiology, SRTM Medical College, Ambejogai, India \\ *Corresponding author
}

\begin{abstract}
A B S T R A C T
Keywords

HIV-Seropositive, Opportunistic

infections,

CD4

Cells count.

Article Info

Accepted:

14 June 2017

Available Online:

10 July 2017

Human Immunodeficiency Virus (HIV) is the most significant emerging infectious pathogen of the $20^{\text {th }}$ Century. The progressive destruction of the immune system by chronic HIV infection leading to progressive fall in level of $\mathrm{CD}_{4}$ cells is responsible for the occurrence of infections by opportunistic micro-organisms. The pattern of Opportunistic infection in people living with HIV/AIDS attending $\mathrm{CC}$ was studied. Detailed history taking, clinical examination and laboratory tests were carried out in 480 patients, Male-162 (51.60\%) and Female 152 (48.40\%). Out of 480 patients $314(65.41 \%)$ were affected by opportunistic infections and commonly observed were diarrhea $(22.92 \%)$, acute respiratory infections $(22.61 \%)$, candidiasis $(19.10 \%)$, pulmonary tuberculosis $(18.47 \%)$, pyoderma $(3.18 \%)$, penicilliosis $(0.6 \%)$ and herpes zoster $(0.6 \%)$. Finding points to be importance of early diagnosis and treatment of opportunistic infections in order to improve quality and expectations of life.
\end{abstract}

\section{Introduction}

HIV is the initial causative agent in AIDS, most of morbidity and mortality seen in immunocompromised patient results from opportunistic infections that take advantage of lowered cellular and humoral defences of the patients (Chakraborty et al., 2008). India is the country with second largest population of HIV infected individuals. The emergence of pandemic spread of AIDS constitute the greatest challenge to public health in modern time, with changing scenario of AIDS epidemic a host of opportunistic infections add to the present epidemic state of some existing infections like tuberculosis (Dabla et al., 2015). Opportunistic infections remain frequent in the ART era even in populations where access to medical care in considered satisfactory, these diseases can arises with any level of viral load and $\mathrm{CD}_{4}+\mathrm{T}$ cell count (Galisteu et al., 2015). Indian guidelines and western country guidelines have certain differences; wherever possible, that gap should be bridged. Developed countries initiate ART at higher $\mathrm{CD}_{4}$ count (Bhuvana et al., 2015). There are a lot of Viral, Bacterial, Fungal and Protozoan pathogens associated with AIDS, changing symptomatology and pathology of disease HIV prepares ground for successful invasion by opportunistic infections that are etiological killer of patients 
in the absence of formal functioning immune system (Sandhu et al., 2013).

\section{Materials and Methods}

The pattern of Opportunistic infections in patients was already diagnosed HIV positive, attending CC was studied. Detailed history taking, clinical examinations, and laboratory test were carried out for diagnosis of Opportunistic infections. These Opportunistic infections was diagnosed on the basis of standard clinical definition and laboratory procedures. These Opportunistic infections co-related according to level of $\mathrm{CD}_{4}$ cell count.

\section{Results and Discussion}

A total number of 480 patients were examined those attending CC. Out of which 314 $(65.41 \%)$ patients were affected by opportunistic infections. In these out of 314 patients, $162(51.60 \%)$ males and 152 $(48.40 \%)$ females were affected by Opportunistic infections.

Distribution of sex among opportunistic infections in seropositive patients

$48.40 \%$

\section{Male}

\section{$51.60 \%$}

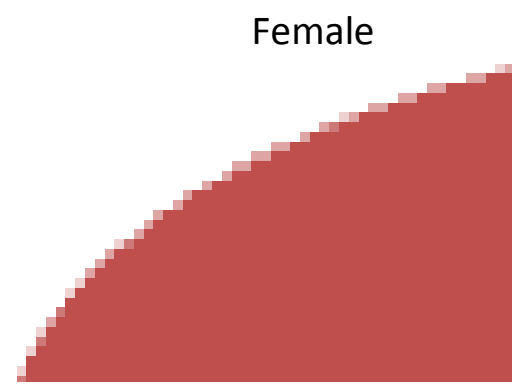

affected by opportunistic infections.

In these out of 314 patients, $162(51.60 \%)$ males and $152(48.40 \%)$ females were

Distribution of opportunistic infections among seropositive patients

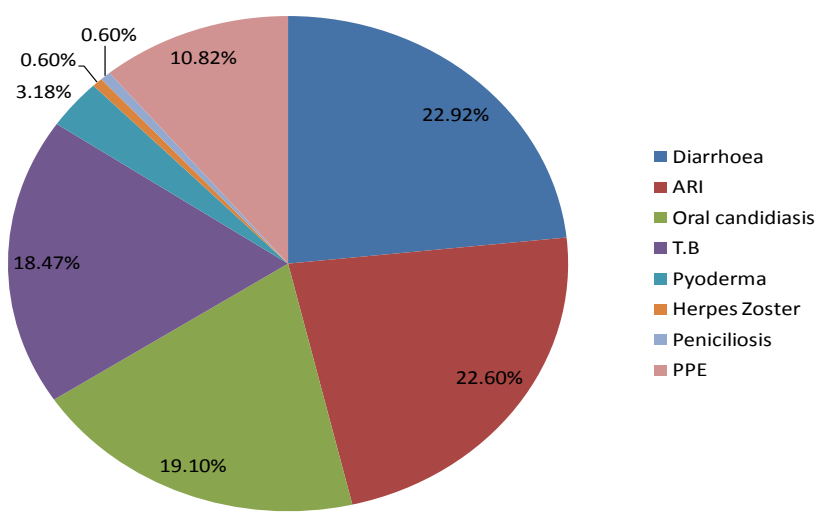


In Opportunistic infections $72(22.92 \%)$ patients had diarrhea by most of coccidian parasites such as Cryptosporidium, Isospora and Cyclospora was observed followed by
Oral Candidiasis 19.10\%, Tuberculosis $18.47 \%$, Pyoderma $3.18 \%$, Penicilliosis $0.6 \%$ and Herpes Zoster $0.6 \%$.

\section{Categorization of opportunistic infections according to level of $\mathrm{CD}_{4}$ cell counts}

\begin{tabular}{|c|l|l|l|l|l|l|}
\hline $\mathrm{CD}_{4}$ Count & Diarrhea & $\begin{array}{l}\text { Oral } \\
\text { Candidiasis }\end{array}$ & T.B & Pyoderma & Peniciliosis & $\begin{array}{l}\text { Herpes } \\
\text { Zoster }\end{array}$ \\
\hline$\leq 200$ & 60 & 32 & 36 & 07 & 02 & 01 \\
\hline $200-399$ & 08 & 23 & 18 & 01 & -- & -- \\
\hline$\geq 400$ & 04 & 05 & 04 & 02 & -- & 01 \\
\hline Total \% & $\begin{array}{l}72 \\
(22.92 \%)\end{array}$ & $\begin{array}{l}60 \\
(19,10 \%)\end{array}$ & $\begin{array}{l}58 \\
(18.47 \%)\end{array}$ & $10(3.18 \%)$ & $02(0.6 \%)$ & $02(0.6 \%)$ \\
\hline
\end{tabular}

It is found that the patients with $\mathrm{CD}_{4}$ Cell count $\leq 200$ cell $/ \mu 1$ were affected more by opportunistic infections rather than $\mathrm{CD}_{4}$ Cell count in between 200-399 and $\geq 400 \mathrm{cell} / \mu 1$.

In the present study out of 480 patients 314 patients $(65.41 \%)$ were affected by one or more opportunistic infections $61.7 \%$ in HIV seropositive patients (Saidu et al., 2009). Prevalence of opportunistic infections was found $50.63 \%$ in a study of Bhuvana et al., (2014). In our study found males 162 $(51.62 \%)$ and Females 152 (48.40\%) were affected. In different studies the percentage of males and females vary for opportunistic infections. Takalkar et al., (2012) was found that $60.9 \%$ males and $39.1 \%$ females were affected, and Agarwal et al., (2015). Among the opportunistic infections Diarrhea was found in 72(22.92\%) patients. Prevalence of diarrhea in HIV positive patient was $41.7 \%$ by Takalkar et al., (2012) 35\% by Kulkarni et al., (2009) 55.8\% by Basak et al., (2010) and 49\% by Rajeshwari Rao et al., (2016). The prevalence of Oral Candidiasis is $19.1 \%$ in our study. Prevalence of Oral candidiasis 14.2\% was found by Bhaumik et al., (2013) and $11.8 \%$ by Moges et al., (2014) in their studies. Prevalence of Tuberculosis in our study is $18.47 \%$ among the opportunistic infections. It is found close with study $17.1 \%$ by Bhaumik et al., (2013) But $33 \%$ by Sandhu and $57 \%$ by Chakrabarty. In our study pyoderma is found in $3.18 \%$ patients, which is found close to the study $3.2 \%$ by P Bhaumik et al., (2013). The percentage of penicilliosis and herpes zoster is $0.6 \%$ in our study. It is found that the percentage of opportunistic infections is more in patients whose $\mathrm{CD}_{4}$ count below 200 compare to cell/ul as compare to $\mathrm{CD}_{4} \geq 400$ cell/ul. This is found same with study by Agarwal. The pattern of Opportunistic infections in a particular area helps the attending physician to be on the lookout for them take prompt therapeutic measures.

In conclusion, significant risk factors for opportunistic infections in seropositive patients are mostly associated with $\mathrm{CD}_{4}$ Cell count level. $\mathrm{CD}_{4}$ Cell count and start of ART reflects the prevalence of opportunistic infections high in most of studies, but finding point to the importance of early diagnosis and treatment of opportunistic infections in order to improve quality and expectancy of life.

\section{References}

Agarwal, S.G., R.M. Powar, Tankhiwale, S. 2015. Study of opportunistic infections in HIV-AIDS Patients and their CO- 
relation with $\mathrm{CD}_{4}+$ cell count. Int. $J$. Curr. Microbiol. App. Sci., 4(6): 848861.

Basak, S., Bose, S., Mallick, S.K., et al. 2010. Intestinal parasitic infections in HIV seropositive patients-A study. J. Clin. Diag. Res., 4: 2433-2437.

Bhaumik, P., Debnath, K. and Sinha, B. 2013. Spectrum of opportunistic infections among HIV/AIDS patients of Tripura. JIACM, 14(3-4): 218-21.

Bhuvana, K.B., Hema, N.G. and Patil, R.T. 2015. Prevalence and risk factors for opportunistic infections in HIV patients who developed adverse drug reactions (ARDs) to antiretroviral therapy(ART) in a tertiary-care teaching hospital. Natl. J. Physiol. Pharm. Pharmacol., 5: 200206.

Chakraborty, N., Mukherjee, A., Santra, S., et al. 2008. Current trends of opportunistic infections among HIV-Seropositive patients from Eastern India. Jpn. J. Infect. Dis., 61: 49-53.

Dabla, V., Gupta, A.K. and Singh, I. 2015. Sprectum of opportunistic infections among HIV seropositive patients in Delhi region -a study by Delhi state AIDS control society. J. Med. Disord., 3: 1 .

Galisteu, K.J., Cardoso, L.V., Furini, A.A., et al. 2015. Opportunistic infections among individuals with HIV-1/AIDS in the highly active antiretroviral therapy era at a quaternary level care teaching hospital. Rev. Soc. Bras. Med. Trop., 48(2): 149-156.
Kulkarani, S.V., R. Kairon, S.S. Sane, et al. 2009. Opportunistic parasitic infections in HIV/AIDS patient presenting with diarrhea by the level of immunosupression. Indian J. Med. Res., 130: 63-66.

Moges, N.A., Kassa, G.M. 2014. Prevalence of opportunistic infections and associated factors among HIV positive patients taking Anti-retroviral therapy in DebreMarkos Refferal hospital, Northwest Ethiopia. J. AIDS Clin. Res., 5(5): $1-6$.

Rao, R.P. 2016. Study of opportunistic intestinal parasitic infections in HIV seropositive patients at a tertiary care teaching hospital in Karnataka, India. Int. J. Contemporary Med. Res., 3(8): 2219-2222.

Saidu, A.S., Bunza, M.D.A., Abubakar, U., et al. 2009. A survey of opportunistic infections in HIV seropositive patients attending major hospitals of Kebbi state, Nigeria. Bayero J. Pure and Appl. Sci., 2(1): 70-74.

Sandhu, A. and Samra, A.K. 2013. Opportunistic infections and disease implications in HIV/AIDS. IJPSI, 2(5): 47-54.

Takalkar, A.A., G.S. Saiprasad, V.G. Prasad et al. 2012. Study of opportunistic infections in HIV seropositive patients admitted to community care centre (CCC), KIMS Narketpally. Biomed. Res., 23(1): 139-142.

\section{How to cite this article:}

Virendra S. Kolhe and Sanjay R. More. 2017. Study of Opportunistic Infections in HIV Seropositive Patients in Tertiary Care Hospital, Maharashtra, India. Int.J.Curr.Microbiol.App.Sci. 6(7): 686-689. doi: https://doi.org/10.20546/ijcmas.2017.607.084 